\title{
QUANTUM CHEMICAL DESIGNING OF TRIPHENYLAMINE DYES WITH D-A-П-A CONFIGURATION FOR DYE SENSITIZED SOLAR CELLS: MOLECULAR ENGINEERING THROUGH FIRST-PRINCIPLES CALCULATIONS
}

\author{
MUHAMMAD RAMZAN SAEED ASHRAF JANJUA* \\ Department of Chemistry, King Fahd University of Petroleum \& Minerals (KFUPM) Dhahran 31261, Kingdom of Saudi Arabia
}

The design of triphenylamine dyes with D-A- $\pi$-A structural configuration for electro-optic modulation indicates that the selection and combination of appropriate conjugated bridge in dye sensitizer plays an important role to design efficient dyes for Dye Sensitized Solar Cells.

Short Running Title

The Design of Dye Sensitized Solar Cells (DSSC)

\begin{abstract}
In this research article, we have designed triphenylamine (TPA) dyes with D-A- $\pi$-A structure and their electro-optical and charge injection properties have been calculated. The computational techniques are used to study the effect of additional acceptor in $\pi$-conjugated systems on absorption spectra and electron injection of the dyes. All the dyes have shown absorbance in visible region. The effect of additional acceptor on the performance of sensitizers in dye sensitized solar cells has also been determined. In theoretical examination electron injection efficiency $\left(\Phi_{\text {inject }}\right)$ and light harvesting efficiency (LHE) have been calculated. The results indicate that the combination and selection of appropriate conjugated bridge in dye sensitizer is an important way to design efficient dyes.
\end{abstract}

Keywords: Triphenylamine dyes, DFT, Dye sensitized solar cells, Additional acceptor.

\section{INTRODUCTION}

Significant attention has been attracted by dye sensitized solar cells (DSSCs) as alternatives to traditional solar cells, owing to their low-cost fabrication combined with high solar energy to electricity power conversion efficiency (PCE) [1,2]. Increasing population and rapidly depleting fossil fuel forced the scientific community to develop efficient renewable energy resources. Among renewable resources, solar energy has bright future. Solar cells can be use for small as well as large scale, especially important for those areas where electricity supply infrastructure is difficult to install $[1,2]$.

DSSCs show the capability to produce low-cost electricity due to its economical and easy manufacturing [1-3]. It has already been well established that the dye plays an important role to alter the efficiency of DSSC [4]. In DSSC, dye plays a role of light absorber and determine the suitability of DSSC for specific area of world. Unique properties of organic dyes make them a strong candidate for DSSC. Organic dyes are easy to synthesize and purify, display high molar absorption coefficient, higher structural flexibility.

It is also important to mention that organic dyes have some drawbacks. One non-ignorable one is their relatively narrow absorption spectrum. Therefore, in order to achieve highly efficient DSSCs, photosensitizers must absorb and convert a broad wavelength of light in the solar spectrum to enhance the light harvesting efficiency (LHE) [5]. It is demonstrated that the extension of $\pi$-conjugated systems leads to a red-shift of absorption wavelength maxima $\left(\lambda_{\max }\right)$, broadening of the absorption profile and enhancement of the molar extinction coefficient [5]. Various $\pi$-conjugated bridges, such as benzene, thiophene and benzothiadiazole have been tested to extend their absorption towards the near-infrared region. Interestingly, studies have shown that in addition to optimizing the optical properties of the dye, increasing the number of thiophene $\pi$-bridging units tends to result in an increase in power conversion efficiency [6].

Laboratory development of D- $\pi$-A dyes often invokes a trial-and-error approach, which requires extensive chemical synthesis and expensive materials processing with slow progress. In this regard, theoretical screening of potential organic dyes using state-of-the-art first principles computation shows a great promise, significantly reducing the cost to develop efficient dyes and expediting discovery of new ones.

In a few decades, lot of efforts have been devoted for the designing of metal free organic dyes. In D- $\pi$-A format both electron-donating (D) and electron-accepting (A) groups linked by a $\pi$-conjugated bridge exhibiting broad and intense absorption spectra, have been proposed as being one of the most promising organic dye sensitizers [7-11]. It has been reported that incorporation of additional acceptor facilitates electron transfer from the light absorbing donor side to the anchoring acceptor side and it has a diverse effect on the photovoltaic performance in the D-A- $\pi$-A system [12-14]

In the present study, we have designed efficient dye sensitizers using triphenylamine (TPA) as an electron donor (D), a cyanoacrylic acid moiety as an electron acceptor (A) and different $\pi$-spacers as bridging components. Every sensitizer has different number of nitrogen atoms.

\section{COMPUTATIONAL METHODs}

Structures of dyes were optimized using B3LYP functional [15-17] and $6-31+G^{*}[18]$ basis set. A tight SCF convergence criteria $\left(10^{-8}\right.$ a.u. $)$ and integration grid of $10^{-8}$ were used for all calculations. Frequency calculations have been performed on the optimized geometry to verify the nature of the computed geometries. The lack of imaginary values in the wave numbers calculations indicated the successful geometry optimization. Conventional exchange-correlation functionals are not good for the simulation of absorption spectra especially for compounds with significant charge-transfer (CT) character $[19,20]$. Therefore selection of suitable functional is very important to describe the absorption spectroscopy of organic dyes with $\mathrm{D}-\pi-\mathrm{A}$ structure. For a reasonable computational effort, the state of the art DFT/TDDFT computational methodologies provide reasonable results and reproduce well the optical properties of various organic dyes [6,21-23]. We first examined the effect of the functionals and basis set on $\lambda_{\max }$ of reference dye. CAM-B3LYP/6$31+\mathrm{G}^{*}$ is considered to be the most reliable methodology that produced result comparable to experimental value $[24,25]$. This methodology is used to simulate the UV/Vis spectra of quantum chemically designed dyes. Coulombattenuating method CAM-B3LYP functional, which is long-range corrected form of B3LYP, was used to calculate absorption spectra of designed dyes [26]. Success of this functional for determination of transition energies for a series of organic dyes is already proven [26]. Optimized structures were used to compute absorption wavelength maxima $\left(\lambda_{\max }\right)$, excitation energy $\left(\mathrm{E}_{\mathrm{g}}\right)$ and oscillator strengths $(f)$ for the 20 states in the frame work of TD-DFT theory with CAM- B3LYP functional [27]. Solvent effect (methanol) was undertaken using conductor-like polarizable continuum model (CPCM) [28].

\section{RESULTS AND DISCUSSION}

In this article, we have presented the results of theoretical designing of efficient sensitizers for dye sensitized solar cells. The designed dyes consist of triphenylamine as donor, cyanoacrylic acid as electron acceptor, different acceptors and $\pi$-spacer in middle. Triphenylamine and cyanoacrylic acid are widely use to designed dyes. Triphenylamine is excellent electron donor and widely used in organic photovoltaic functional materials [29]. TPA prevents aggregation due to its non-planar structure. It also showed very good hole- 
transport properties. Triphenylamine based dyes are extensively applied in DSSCs and showed high conversion efficiencies [3]. Cyanoacrylic acid is widely used as an anchor/acceptor group and shows excellent charge withdrawing ability [30]. In addition, the cyanoacrylic acid anchor favors better photoelectrochemical properties. The structures of these dyes are given in Figure 1.

\subsection{Energy level alignment}

The photoinjection of electrons from excited dye to $\mathrm{TiO}_{2}$ conduction band increases the electron density in the porous electrode thin film, resulting in shifting the quasi-Fermi level EF closer to the conduction band edge Ec. Theoretical models assume that the difference between $\mathrm{E}_{\mathrm{F}}$ of $\mathrm{TiO}_{2}$ and the electrolyte redox potential Eredox be the induced photovoltage [31]. That is true for the open-circuit condition in which there is no current flow through the $\mathrm{TiO}_{2}$ interface and electrolyte/counter electrode interface. However, under maximum power conditions, additional potential differences across these two interfaces should be considered The energy levels of HOMOs and LUMOs of the dye sensitizer should match with iodine/iodide redox potential and the conduction band edge level of the $\mathrm{TiO}_{2}$ semiconductor [31]. $\mathrm{E}_{\mathrm{Homo}}, \mathrm{E}_{\text {uyo }}$ and energy gap are given in Table 1. Electrons will be favorably transferred from the excited state of dye to the $\mathrm{TiO}_{2}$ conduction band edge because LUMOs of all the dyes studied in this work lie above the $\mathrm{TiO}_{2}$ conduction band edge $(4.00 \mathrm{eV})[32]$. Level of HOMOs of all the investigated dyes was below the iodide redox potential $(4.80 \mathrm{eV})$ [33]. This indicates fast dye regeneration and minimum charge recombination between oxidized dye molecules and photoinjected electrons. From Table 1, it is clear that HOMO-LUMO energy gap significantly decreased from dye 1 to dye 4 due to increase of number of nitrogen atoms in $\pi$-spacer. HOMO and LUMO of studied dyes are given in Figure 2. For all dyes HOMO are on donor while LUMO are on acceptor. This situation indicating the favorable charge transfer from donor to acceptor (TPA to Acid moiety).

Table 1. $\mathrm{E}_{\text {номо }}, \mathrm{E}_{\text {Luмо }}$, and Energy Gap ( $\left.\mathrm{E}_{\mathrm{g}}\right)$ of studied dyes $(\mathrm{eV})$

\begin{tabular}{|c|c|c|c|}
\hline Dye & $\mathrm{E}_{\text {номо }}$ & $\mathrm{E}_{\text {LUмо }}$ & $\mathrm{E}_{\mathrm{g}}$ \\
\hline 1 & -5.000 & -2.815 & 2.185 \\
\hline 2 & -5.034 & -3.240 & 1.794 \\
\hline 3 & -5.182 & -3.413 & 1.769 \\
\hline 4 & -5.348 & -3.638 & 1.709 \\
\hline
\end{tabular}

\subsection{UV-Vis spectra of dyes}

After extensive work on electronic structure calculations of isolated molecules, a consensus on a suitability of computational techniques for studying optical and electronic properties of dyes in computational chemistry community is developed. To stimulate absorption spectra of dyes, TD-DFT calculations were performed at CAM-B3LYP/6-31+G* level of theory. In TDDFT calculations of absorption spectra, the 20 lowest singlet-singlet transitions were determined.

The computed maximum absorption wavelengths $\left(\lambda_{\max }\right)$, absorption energy, oscillator strengths $(f)$ and nature of the transitions are summarized in Table 2. Light harvesting efficiency (LHE) is another factor, which determines the efficiency of DSSC. Generally, high LHE is required to get maximum photocurrent. The following expression is used to calculate the LHE [34]:

$$
L H E=1-10^{-f} \Rightarrow(1)
$$

Where, $f$ is the oscillator strength of the dye molecules, the larger the $f$ could fulfil a better light capturing. For a DSSCc to work properly, it is clear that both ground state oxidation potential energy $\left(\mathrm{E}^{\mathrm{dye}}\right)$ and excited state oxidation potential energy $\left(\mathrm{E}^{\mathrm{dye}}\right)$ of the dyes have to match the redox potential $(-4.8 \mathrm{eV}$ vs vaccum) of the iodine/iodide redox couple and the conduction band $(-4.0 \mathrm{eV}$ vs vaccum) of the $\mathrm{TiO}_{2}$ electrode, respectively. Which roughly evaluated using the formula, $\mathrm{E}^{\mathrm{dye} *}=\mathrm{E}^{\text {dye }}-\mathrm{E}_{00}$

Values of LHE are given in Table 2. Although there is no clear trend of $\boldsymbol{\lambda}_{\text {max }}$ ,,$f$ and LHE. However, $\Delta G^{\text {inject }}$ increase with the increase of nitrogen atom in $\pi$-spacer This may be due to decrease of band gap with increase of number of nitrogen atom in $\pi$-spacer. The computed results show that the strongest absorption peaks for all dyes mainly related to the transition from the HOMO to LUMO. It indicates intramolecular charge transfer (ICT) when the transition occurs.
Table 2.Computed maximum absorption wavelengths $(\lambda \mathrm{nm})$, absorption energy $\left(\mathrm{E}_{\mathrm{g}}, \mathrm{eV}\right)$,oscillator strengths $(f)$, light harvesting efficiency(LHE) and transition natures of dyes.

\begin{tabular}{|c|c|c|c|c|c|}
\hline Dye & $\lambda_{\max }$ & $\mathrm{E}_{\mathrm{g}}$ & $f$ & LHE & Main configurations* \\
\hline 1 & 474.17 & 2.610 & 2.362 & 0.996 & $\mathrm{H} \rightarrow \mathrm{L}(51 \%)$ \\
\hline 2 & 552.65 & 2.243 & 1.631 & 0.977 & $\mathrm{H} \rightarrow \mathrm{L}(60 \%)$ \\
\hline 3 & 496.72 & 2.496 & 1.693 & 0.980 & $\mathrm{H} \rightarrow \mathrm{L}(46 \%)$ \\
\hline 4 & 445.21 & 2.784 & 1.442 & 0.964 & $\mathrm{H} \rightarrow \mathrm{L}(54 \%)$ \\
\hline
\end{tabular}

\subsection{Incident photon-to-electron conversion efficiency (IPCE)}

The incident photon-to-electron conversion efficiency (IPCE) is determined by the light harvesting ability (LHE), the overall charge collection efficiency $\left(\Phi_{\text {iniect }}\right)$ and the overall electron injection efficiency $\left(\eta_{\text {collect }}\right)$. IPCE is one of main parameters used to determine the overall efficiency of DSSCs and is expressed by the following equation[35]:

$$
I P C E=L H E \times \Phi_{i n j} \times \eta_{c} \Rightarrow(2)
$$

$\eta_{\text {collect }}$ is considered a constant for the same DSSCs with only different dyes. As a result, IPCE can be enhanced by improving the LHE and $\Phi$ according to eqn (2), in order to obtain a high IPCE, the efficient organic dyes used in DSSCs should have a large LHE. The LHE of dye was increased with an increase of thiophene rings from dye $2(0.977)$ to dye $1(0.996)$. Whereas presence of two thiazole rings with one thiadiazole fused with benzene ring as shown in dye $3(0.980)$ was a better combination than dye 2. While two thiadiazole rings along with one thiadiazole fused with benzene ring was least efficient system (dye 4) among the studied dyes (1-4). We can conclude that the various combinations of $\pi$-conjugated systems as shown in table 4 may be efficient strategy to obtain high IPCE if other factor factors especially $\Phi_{\text {inject }}$ should increase or maintain at the same level. IPCE can be enhanced by improving the $\Phi$ that is related to the driving force $\left(\Delta G^{\text {inject }}\right)$ of the electron injection from the photoinduced excited states of organic dyes to the $\mathrm{TiO}_{2}$ surface. Generally larger $\Delta G^{\text {inject }}$ leads to larger $\Phi_{\text {inec. }}$.In short, four organic dyes (1-4) with D-A- $\pi$-A structure, having thiophene, thiadiazole, and thiazole, moieties as auxiliary acceptors and $\pi$-framework as well have been studied as shown in table 4 . While triphenylamine donor and cyanoacrylic acid as acceptor were playing a vital role in charge transfer from left to right.

Table 4: Various combinations of rings used within triphenylamine donor and cyanoacrylic acid acceptor in studied dyes (1-4)

\begin{tabular}{|c|c|}
\hline dyes & thiophene thiadiazole \\
\hline 1 & two thiophene rings + two fused thiophene rings \\
\hline 2 & two thiophene rings + one thiadiazole fused with benzene ring \\
\hline 3 & two thiazole rings + one thiadiazole fused with benzene ring \\
\hline 4 & two thiadiazole rings + one thiadiazole fused with benzene ring \\
\hline
\end{tabular}

\subsection{Electron injection from dyes to $\mathrm{TiO}$}

Computation of electron injection rate is very useful to study photovoltaic data. The following equation is used to calculate free energy change (in eV) for the electron injection:

$$
\Delta G^{\text {inject }}=E_{O X}^{\text {dye* }}-E_{C B}^{\mathrm{TiO}_{2}} \Rightarrow(3)
$$

where $E_{O X}^{d y e^{*}}$ is the oxidation potential of the dye in the excited state, $E_{\mathrm{TB}_{2}}^{\mathrm{TiO}}$ is the reduction potential of the conduction band of theTiO $\left(E_{C B}^{\mathrm{TiO}_{2}}=4.0 \mathrm{eV}\right)$.

$$
E_{O X}^{d y e^{*}}=E_{O X}^{d y e}-\lambda_{\max }^{I C T} \Rightarrow(4)
$$

where $E_{O X}^{d y e}$ is the redox potential of the ground state. $E_{O X}^{d y e}$ can be estimated as negative $\mathrm{E}_{\text {номо }}[36]$. Where in this equation $\lambda_{\max }^{I C T}$ is the energy of the intra 
molecular charge transfer (ICT). By using this scheme, we calculated, $\Delta G^{\text {inject }}$ as well as $E^{d y e}$ and $E^{d y e^{*}}$ for dyes and the results are listed in Table 3. We found that all the calculated $\Delta G^{\text {inject }}$ values are negative, which means that the dye's excited state lies above the $\mathrm{TiO}_{2}$ conduction band edge and favors the injection of the electron from the excited state of dye to the $\mathrm{TiO}_{2}$ conduction band edge.

As discussed above, IPCE mainly depends upon light harvesting efficiency (LHE) and electron injection efficiency $(\Phi$,$) . A positive increase in these$ factors will lead to better efficiency of dyes in dye sensitized solar cells. From result it is clear that $\Delta G^{\text {inject }}$ increase with the increase of nitrogen atom in $\pi$-spacer (as indicated by more negative $\Delta G^{\text {inject }}$ values). This may be due to decrease of band gap with increase of number of nitrogen atom in $\pi$-spacer.

Table 3. $\Delta G^{\text {inject }}(\mathrm{eV})$ and oxidation potential $(\mathrm{eV})$ of dyes.

\begin{tabular}{|c|c|c|c|}
\hline \multirow{2}{*}{ Dye } & $\Delta G^{\text {inject }}$ & $E_{O X}^{\text {dye* }}$ & $E_{O X}^{\text {dye }}$ \\
\hline 1 & -1.610 & 2.390 & 5.000 \\
\hline 2 & -1.209 & 2.791 & 5.034 \\
\hline 3 & -1.314 & 2.686 & 5.182 \\
\hline 4 & -1.436 & 2.564 & 5.348 \\
\hline
\end{tabular}

\section{CONCLUSIONS}

In this account, molecular engineering of triphenylamine dyes containing additional acceptor group with pi-spacer was reported through first-principles calculations. All the dyes have shown absorbance in visible region. The study of electronic structures indicates that HOMO and LUMO energies are significantly affected by changing the nature of $\pi$-spacer. Increasing the number of nitrogen atoms in $\pi$-spacer significantly decreased the HOMOLUMO energy gap. The results of this theoretical investigation also point out that the various combinations of $\pi$-conjugated systems with additional acceptor is responsible for the increase of electron injection efficiency. The combination and selection of suitable conjugate bridge in dye sensitizer is an important factor to design new dyes with enhanced performance. This study expands the scope to use thiophene, thiadiazole, and thiazole rings as auxiliary acceptors and $\pi$-spacers as well in DSSCs, which will be helpful for future design of efficient organic sensitizers.
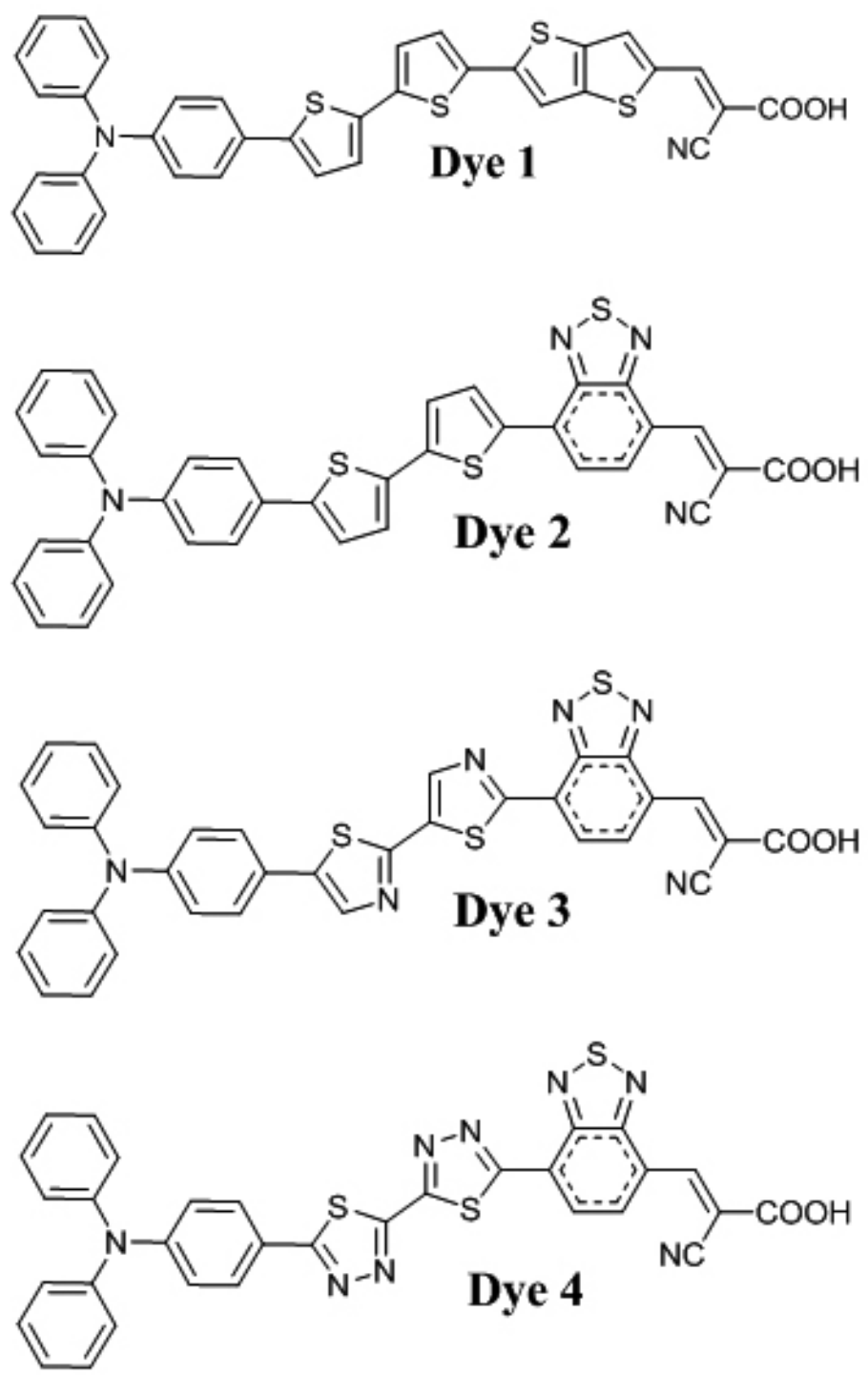

Figure 1.Structures of studied dyes 

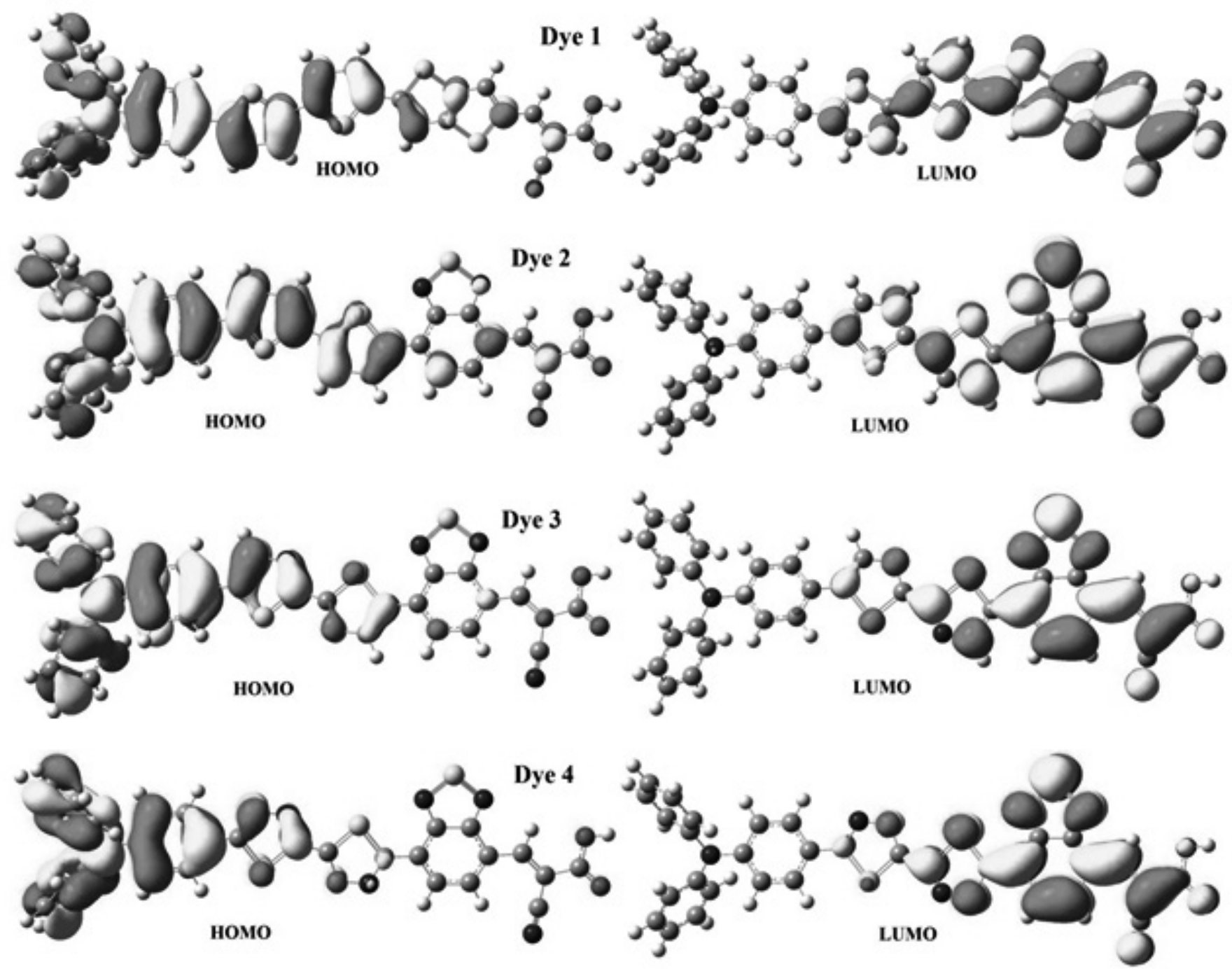

Figure 2: HOMO and LUMO of studied dyes.

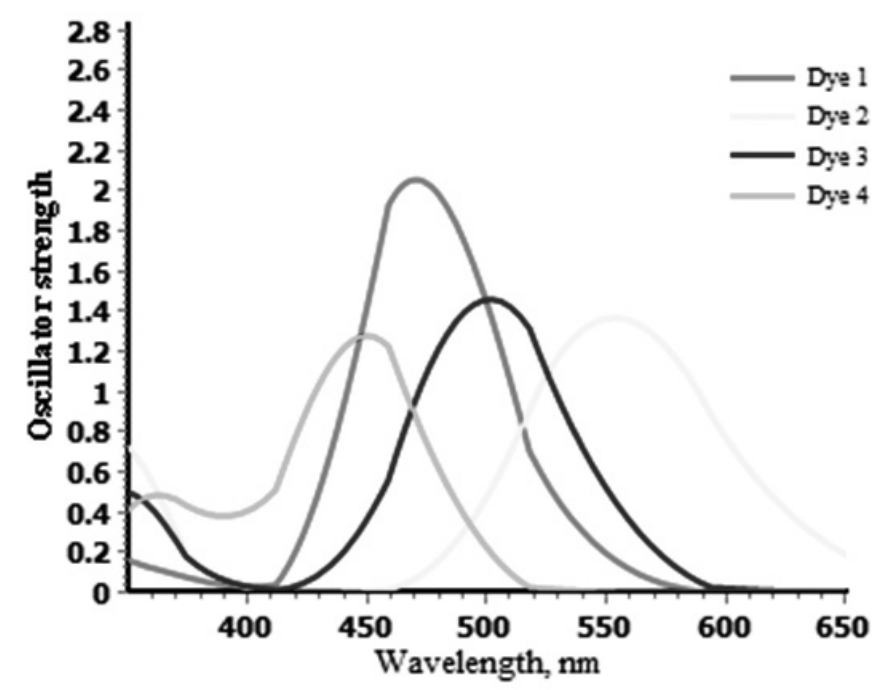

Figure 3.Simulated Absorption spectra of dyes 


\section{ACKNOWLEDGEMENT}

The author would like to acknowledge the support provided by the Deanship of Scientific Research (DSR) at King Fahd University of Petroleum \& Minerals (KFUPM) for funding this work through project No. SR161009.

\section{REFERENCES}

[1] a) J. N. Clifford, E. Martinez-Ferrero, A. Viterisi, and E. Palomares, Chemical Society Reviews 40, 1635 (2011). b) Grätzel, M. Acc. Chem. Res. 2009, 42, 1788.

[2] a) B. O'Regan and M. Gratzel, Nature 353, 737 (1991). b) Hagfeldt, A.; Boschloo, G.; Sun, L. C.; Kloo, L.; Pettersson, H. Chem. Rev. 2010, 110, 6595

[3] A. Mahmood, Solar Energy 123, 127 (2016).

[4] a) T. Funaki, H. Funakoshi, O. Kitao, N. Onozawa-Komatsuzaki, K. Kasuga, K. Sayama, and H. Sugihara, Angewandte Chemie International Edition 51, 7528 (2012). b) S. B. Mane, C-F. Cheng, A. A. Sutanto, A. Datta, A. Dutta, C-H. Hung, Tetrahedron, 71, 42 (2015) 7977-7984.

[5] H. J. Jo, J. E. Nam, D.-H. Kim, H. Kim, and J.-K. Kang, Dyes and Pigments 102, 285 (2014).

[6] S. Kim et al., Journal of the American Chemical Society 128, 16701 (2006).

[7] Y. Gong et al., Chemical Communications 49, 4009 (2013).

[8] X. Ma, X. Mao, S. Zhang, X. Huang, Y. Cheng, and C. Zhu, Polymer Chemistry 4, 520 (2013)

[9] M. Marszalek, S. Nagane, A. Ichake, R. Humphry-Baker, V. Paul, S. M. Zakeeruddin, and M. Gratzel, RSC Advances 3, 7921 (2013).

[10] Y. Ooyama, N. Yamaguchi, I. Imae, K. Komaguchi, J. Ohshita, and Y. Harima, Chemical Communications 49, 2548 (2013).

[11] a) M.R.S.A. Janjua, Z.H. Yamani, S. Jamil, A. Mahmood, I. Ahmad, M. Haroon, M.H. Tahir, Z. Yang, S. Pan, Australian Journal of Chemistry, 69 (2016) 467-472. b) M.R.S.A. Janjua, Inorg. Chem. 51 (2012), 1130611314. c) M.R.S.A. Janjua, M.U. Khan, B. Bashir, M.A. Iqbal, Y. Song, S.A.R. Naqvi, Z.A. Khan, Comput. Theor. Chem. 994 (2012), 34-40.

[12] W. Li, Y. Wu, Q. Zhang, H. Tian, and W. Zhu, ACS Applied Materials \& Interfaces 4, 1822 (2012).

[13] Y. Wu, X. Zhang, W. Li, Z.-S. Wang, H. Tian, and W. Zhu, Advanced Energy Materials 2, 149 (2012).

[14] S. Qu, C. Qin, A. Islam, Y. Wu, W. Zhu, J. Hua, H. Tian, and L. Han, Chemical Communications 48, 6972 (2012).

[15] A. D. Becke, The Journal of Chemical Physics 98, 5648 (1993).

[16] C. Lee, W. Yang, and R. G. Parr, Physical Review B 37, 785 (1988).

[17] M.R.S.A. Janjua, A. Mahmood, F. Ahmed, Can. J. Chem. 91 (2013), 1303-1309

[18] J. Zhang, H.-B. Li, S.-L. Sun, Y. Geng, Y. Wu, and Z.-M. Su, Journal of Materials Chemistry 22, 568 (2012).

[19] J. Autschbach, ChemPhysChem 10, 1757 (2009).

[20] A. Dreuw and M. Head-Gordon, Chemical Reviews 105, 4009 (2005).

[21] J. Preat, C. Michaux, D. Jacquemin, and E. A. Perpète, The Journal of Physical Chemistry C 113, 16821 (2009).

[22] D. Jacquemin, V. Wathelet, E. A. Perpète, and C. Adamo, Journal of Chemical Theory and Computation 5, 2420 (2009).

[23] M. Pastore, E. Mosconi, F. De Angelis, and M. Grätzel, The Journal of Physical Chemistry C 114, 7205 (2010).

[24] A. Irfan, R. Jin, A. G. Al-Sehemi, and A. M. Asiri, Spectrochimica Acta Part A: Molecular and Biomolecular Spectroscopy 110, 60 (2013).

[25] A. A. Hasanein, Y. R. Elmarassi, and E. N. Kassem, Journal of Molecular Modeling 22, 115 (2016).

[26] T. Yanai, D. P. Tew, and N. C. Handy, Chemical Physics Letters 393, 51 (2004).

[27] J. P. Perdew, K. Burke, and M. Ernzerhof, Physical Review Letters 77, 3865 (1996)

[28] V. Barone and M. Cossi, The Journal of Physical Chemistry A 102, 1995 (1998).

[29] Z. T. ZENG Juan, ZANG XuFeng, KUANG DaiBin, MEIER Herbert, CAO DeRong, SCIENCE CHINA Chemistry 56, 505 (2013).

[30] S. Agrawal, P. Dev, N. J. English, K. R. Thampi, and J. M. D. MacElroy, Journal of Materials Chemistry 21, 11101 (2011).

[31] a) P. Qin, X. Yang, R. Chen, L. Sun, T. Marinado, T. Edvinsson, G. Boschloo, and A. Hagfeldt, The Journal of Physical Chemistry C 111, 1853 (2007).b) S. Södergren, A. Hagfeldt, J. Olsson, and S. E. Lindquist., "Theoretical Models for the Action Spectrum and the
Current-Voltage Characteristics of Microporous Semiconductor-Films in Photoelectrochemical Cells", J. Phys. Chem., 98, 5552-5556 (1994). c) R. Gómez, and P. Salvador:" Photovoltage Dependence on Film Thickness and Type of Illumination in Nanoporous Thin Film Electrodes According to a Simple Diffusion Model", Solar Energy Materials \& Solar Cells, 88, 377-388 (2005). d) J. Ferber, R. Stangl, and J. Luther, "An electrica model of the dye-sensitized solar cell”, Sol. Energy Mater. Sol. Cells, 53, 29-54 (1998).

[32] M. Gratzel, Nature 414, 338 (2001).

[33] G. Zhang, Y. Bai, R. Li, D. Shi, S. Wenger, S. M. Zakeeruddin, M. Gratzel, and P. Wang, Energy \& Environmental Science 2, 92 (2009).

[34] H. S. Nalwa, Handbook of Advanced Electronic and Photonic Materials and Devices (Academic, San Diego, CA, 2001).

[35] M. K. Nazeeruddin, A. Kay, I. Rodicio, R. Humphry-Baker, E. Mueller, P. Liska, N. Vlachopoulos, and M. Graetzel, Journal of the American Chemical Society 115, 6382 (1993).

[36] R. G. Pearson, Inorganic Chemistry 27, 734 (1988). 